\title{
LA RECEPCIÓN DE LAS MARAVILLAS DE LA ANTIGÜEDAD EN ESPAÑA A TRAVÉS DE LOS TESTIMONIOS DE VIAJEROS A EGIPTO ENTRE EL S. XII Y LOS ALBORES DEL XVI
}

\author{
The Reception of the Ancient Wonders in Spain through the Testimonies \\ of Travellers to Egypt between the 12th \& the 16th Centuries
}

\author{
Ainhoa De Miguel Irureta \\ ainhoa_de_miguel@hotmail.com \\ Universidad Católica de Murcia. España \\ Fecha de recepción: 10/05/2020 \\ Fecha de aceptación: 07/06/2020
}

\begin{abstract}
RESUMEN: Este estudio pretende analizar las noticias sobre las Pirámides y el Faro de Alejandría en el marco de la Península Ibérica entre la Plena Edad Media y el comienzo de la Edad Moderna a través del examen de los testimonios de viajeros procedentes de al-Andalus y de los reinos cristianos. Así mismo, se intenta demostrar la importancia de esos viajes en la transmisión de conocimientos sobre los grandes monumentos de Egipto y la influencia de la diversa formación y el contexto religioso-cultural de cada uno de los viajeros a la hora de describirlos. Igualmente, se repasará la recepción de estos textos con la finalidad de considerar su papel en las concepciones visuales sobre estas maravillas y el establecimiento de arquetipos. Las fuentes estudiadas comprenden, para el caso de viajeros árabes procedentes de alAndalus, las descripciones de al-Gharnati y de al-Balawi; el testimonio del viajero judío Benjamín de Tudela; y los escritos de los cristianos Pedro Tafur y Pedro Mártir de Anglería. El análisis pone de manifiesto la importancia del viaje como método directo de conocimiento sobre los monumentos antiguos y forma de contrastar las informaciones recibidas de fuentes más antiguas, ya fueran escritas o visuales. Por otra parte, se ha podido comprobar que la mayor o menor exactitud de los datos recogidos por esos viajeros en sus descripciones tiene mucho que ver con la diferente formación, el nivel cultural personal y la influencia del contexto religioso-cultural de cada uno de ellos.
\end{abstract}

Palabras clave: Egipto; pirámides; faro; viajeros; recepción; medievo. 
ABSTRACT: The aim of this study is to analyse the news about the Pyramids and the Lighthouse of Alexandria within the framework of the Iberian Peninsula between the Full Middle Ages and the beginning of the Modern Age through the examination of the testimonies of travellers from al-Andalus and the Christian kingdoms. It also seeks to demonstrate the importance of these travels in the transmission of knowledge about Egypt's great monuments and the influence of the diverse education and religious-cultural context of each of the travellers when describing them. Likewise, the reception of these texts will be reviewed in order to consider their role in visual conceptions about these wonders and the establishment of archetypes. The studied sources include, for the case of Arab travellers from al-Andalus, descriptions by al-Gharnati and al-Balawi; the testimony of the Jewish traveller Benjamin of Tudela; and the writings of the Christian travellers Pedro Tafur and Pedro Mártir de Anglería. The analysis highlights the importance of travel as a direct method of knowledge about ancient monuments and as a way to contrast the information received from older sources, whether written or visual. On the other hand, it has been found that the greater or lesser accuracy of the collected data by these travellers in their descriptions has much to do with the different education, personal cultural level and influence of the religious-cultural context of each of them.

Keywords: Egypt; pyramids; lighthouse; travellers; reception; Middle Ages.

SUMARIO: 1. Introducción. 2. La literatura de viajes y las maravillas. 3. Viajeros de al-Andalus. 4. Benjamín de Tudela. 5. Pedro Tafur. 6. Pedro Mártir de Anglería. 7. Conclusiones. 8. Referencias bibliográficas

\section{INTRODUCCIÓN}

En el contexto del conocimiento sobre las Siete Maravillas del mundo antiguo, las diferentes visiones de las maravillas sitas en Egipto -las Pirámides y el Faro de Alejandría- que trasmitieron distintos viajeros procedentes de la Península Ibérica a lo largo de la Edad Media y principios de la Edad Moderna están íntimamente ligadas a la formación, profesión, intereses e incluso religión de los mismos.

En primer lugar, dos viajeros procedentes de al-Andalus, Abu Hamid al-Gharnati y Yusuf Ibn al-Shaykh al-Balawi, realizaron sendos periplos que les llevaron a Alejandría en diferentes momentos del siglo XII. Ambos reflejan en sus escritos su formación académica y su interés por el estudio de primera mano al medir y dibujar el Faro de Alejandría. No se centraron en recoger testimonios de fuentes clásicas, sino que realizan mediciones propias, como es el caso de al-Balawi, o recogen datos y noticias legendarias que aparecen combinadas con apuntes geográficos objetivos y reales, como hace al-Gharnati.

En el mismo siglo xII, el rabino judío Benjamín de Tudela, también un hombre instruido, realizó un viaje cuya meta fue intentar formar a futuros viajeros decididos a recorrer el mundo, al mismo tiempo que hacer volar la imaginación de los que no podían viajar. Su libro de viaje constituye un género literario prácticamente desconocido en la literatura judía contemporánea a su siglo, y ofrece datos prácticos como el número de días de marcha de una comunidad judía a otra, la seguridad de 
los caminos y vías marítimas, la orografía, a la par que leyendas y tradiciones orales. Sin embargo, su aproximación a las maravillas está fuertemente influenciada por su formación de rabino y su conocimiento de los textos sagrados, sobre todo en el caso de las pirámides.

En el siglo xv, un personaje que se movía en los círculos de la nobleza sevillana, Pedro Tafur, que tenía formación militar, viajó por los tres continentes conocidos y realizó una descripción geográfica, política y social de los lugares visitados. Su viaje no es un itinerario al uso de la época, como eran las peregrinaciones a Tierra Santa, sino que tiene un afán más individualista y humanista; Tafur era un hombre regido por valores religiosos y por el honor del combate, como buen hidalgo castellano, y defendía la lucha armada contra el Islam, pero a su vez se puede percibir en él su gusto y admiración por la formación humanística que se refleja en su obra al mencionar los clásicos griegos y romanos (Villalba Ruiz de Toledo, 2005). Aun así, ese interés «humanístico» no está apoyado en verdadera erudición.

Por otra parte, la verdadera formación humanística se materializa en la obra de Pedro Mejía, ya a comienzos del siglo XVI, donde se pone en evidencia no solo una gran erudición en el manejo de fuentes clásicas, sino el uso de fuentes directas de gran valor histórico, como las noticias de la embajada a Egipto de Pedro Mártir de Anglería en 1501.

A través del análisis de los testimonios de estos viajeros de diferentes culturas presentes en la Península Ibérica de la Plena y Baja Edad Media y los albores de la Edad Moderna, la primera pretensión de este estudio es rastrear las noticias surgidas en la época y lugar mencionados sobre las dos maravillas de la Antigüedad presentes en Egipto ${ }^{1}$. Con ello, intentaremos demostrar, por una parte, la importancia de esos viajes a la hora de transmitir conocimientos de mayor o menor exactitud sobre los grandes monumentos de Oriente, y por otra, la relevancia de la formación y del bagaje religioso-cultural de cada uno de los diferentes viajeros en la visión concreta presente en sus diversos testimonios. Finalmente, con el objetivo de estudiar la influencia de estos escritos y de sus descripciones en las concepciones visuales y establecimiento de arquetipos sobre las maravillas, investigaremos los problemas de recepción de dichos textos.

Planteados estos objetivos y metodología de estudio, comenzaremos presentando un breve contexto sobre la literatura de viajes precedente en relación con las maravillas de la Antigüedad para abordar a continuación el análisis de cada caso particular.

1 Según la lista canónica que precisamente habría de quedar establecida desde el Renacimiento y que además de las Pirámides y el Faro, comprendía los Jardines Colgantes de Babilonia, la Estatua de Zeus de Olimpia, el Templo de Artemisa en Éfeso, el Mausoleo de Halicarnaso y el Coloso de Rodas. 


\section{LA LITERATURA DE VIAJES Y LAS MARAVILLAS}

En época helenística se generalizó la experiencia de la autopsía, el «ver con los propios ojos", popularizándose los textos que describían lugares, edificios y estatuas en los santuarios y ciudades más importantes. Podemos considerar estos textos como las primeras guías de viaje, una literatura periegética que nace ligada a la práctica viajera de los griegos como pueblo habituado al comercio marítimo. Los primeros periplos, en su origen simples tratados de navegación, fueron transformándose en literatura de viaje, que podía reflejar un viaje real, pero la mayoría era fruto de la especulación geográfica o pura fantasía (García Moreno y Gómez Espelosín, 1996, p. 7), haciendo así su aparición lo maravilloso, lo extraordinario, que llevará al surgimiento del relato paradoxográfico y al gusto por las listas de maravillas (Pajón Leyra, 2011, p. 30).

En aquel momento la idea de visitar las maravillas del mundo y poder verlas en persona era remota, pero la costumbre de viajar a templos y santuarios famosos se fue generalizando y de esta forma algunas maravillas surgieron en lugares que desde antiguo atraían a visitantes, como Olimpia o Éfeso. Estos casos apuntan a que la experiencia turística apareció en la Grecia antigua asociada a la religión en la mayoría de las veces, como volverá a suceder con las peregrinaciones en la Edad Media, tanto a Tierra Santa como a Roma. La experiencia del viaje o periégesis suscitaba un gran interés por las obras que provocaban una especial admiración y apareció en el imaginario colectivo la idea de maravilla, que muchos autores pusieron en valor al describir lugares o construcciones dignos de ser admirados. Por otro lado, la fascinación por Egipto ya viene de época imperial romana, por lo que allí se aunaban la seducción de un imperio milenario y la grandiosidad de sus maravillas, que además han sido las que más tiempo han permanecido en pie.

La Antigüedad Tardía, como período de transición largo y complejo, absorbió y sustituyó la cultura clásica por parte de las culturas teocéntricas cristiana e islámica en el plano cultural e ideológico. Los autores cristianos tardoantiguos y medievales tuvieron que enfrentarse al problema de tener que presentar monumentos de claro sentido pagano, como la estatua de Zeus en Olimpia o el templo de Artemisa, por lo que en las listas medievales algunas maravillas se eliminaron, otras se reemplazaron por monumentos bíblicos (por ejemplo, el Artemisión de Éfeso por el Templo de Salomón) y otras se reinterpretaron desde la óptica judeo-cristiana (como las pirámides egipcias, que se identificaron con los graneros de José).

En la Europa medieval, las maravillas, lo extraordinario e incluso las tierras que describían los relatos bíblicos quedaban muy lejos, de ahí que la propia idea de lo maravilloso cambiara, aproximándose más al conocimiento más cercano que aportaba la Biblia y al propio espacio de paisajes más próximos. Europa se desconectó de Bizancio y del legado de la cultura clásica debido al cisma entre el cristianismo occidental y oriental y tras la expansión musulmana del siglo VII, pero la noción 
abstracta de una lista de monumentos antiguos seguía presente en la mente de la Europa occidental (Romer y Romer, 1996, p. 205).

Las listas de maravillas, junto con catálogos de milagros y escritos de viajeros a Roma y Jerusalén, forman el poso perfecto para la proliferación de los Mirabilia Urbis Romae, sobre todo a partir del s. XII, ya en plena Edad Media. De hecho, Epifanio de Constantinopla, también conocido como Epifanio el Monje, escribió a finales del siglo VIII un relato sobre su peregrinación a Alejandría para rezar en sus santos lugares, en la línea de lo que será el precedente de estas guías de viaje medievales. En este texto, se nombra el Faro de Alejandría como la primera de las maravillas, y aparecen las pirámides como los graneros de José:

Hacia occidente, a cuatro días de distancia, está la ciudad de Alejandría (...) En el puerto de Alejandría se alza la torre denominada Pharas [sic], la primera maravilla. Se mantiene unida mediante vidrio y plomo y tiene cincuenta y cinco metros de altura (...) A unos cuatro días de San Macario están los graneros de José, treinta y seis en total².

Por otra parte, Alejandría siempre había cautivado a los viajeros de Al-Andalus, ya que a menudo era su primer puerto de escala en la obligada peregrinación a La Meca; entre los siglos XII y xIV los andalusíes utilizaron el Mediterráneo o las rutas terrestres atravesando todo el norte de África, para llegar al mismo sitio: los Santos Lugares, La Meca y Medina. La ciudad de Alejandría atraía a académicos del Oriente islámico que podían ofrecer enseñanza en materias poco estudiadas en el Occidente, y así ampliar conocimientos, constituyéndose en punto de encuentro y de intercambio cultural.

\section{VIAJEROS DE AL-ANDALUS}

En 1117, un viajero andalusí, natural de Granada, Abu Hamid al-Gharnati, a partir del material recogido y redactado en sus propios viajes y de los datos tomados de la revisión de obras anteriores o coetáneas, recoge acontecimientos sorprendentes que forman parte del género de 'ayā'ib o "relatos de maravillas» (Lévi-Provençal, 2016, pp. 125-126). Entre ellos, también hace referencia al Faro, del que incluye una

2 Epifanio el Monje: Ad modum descriptionis situs orbis, enarratio Syriae, urbis sanctae et sacrorum ibi locorum, Patrologia Graeca, 120, 266: "Tum ad occiduam ejus partem, quator circiter dierum intervalo, sita est urbs Alexandria (...) Atque ad portum Alexandriae structa turris est, quae dicitur Pharas, primum inter miracula. Est autem coagmentata vitro et plumbo, in altitudinem trecentarum sex ulnarum (...) Item a S. Macario distant, itinere dierum quator, repositoria XXXVI Josephi». 
descripción y un croquis en sus obras: Al-Mu'rib 'an ba 'd 'ayā'ib al-Magrib (Bejarano (ed.), 1991) y Tuhfat al-albāb³ [Fig. 1]:

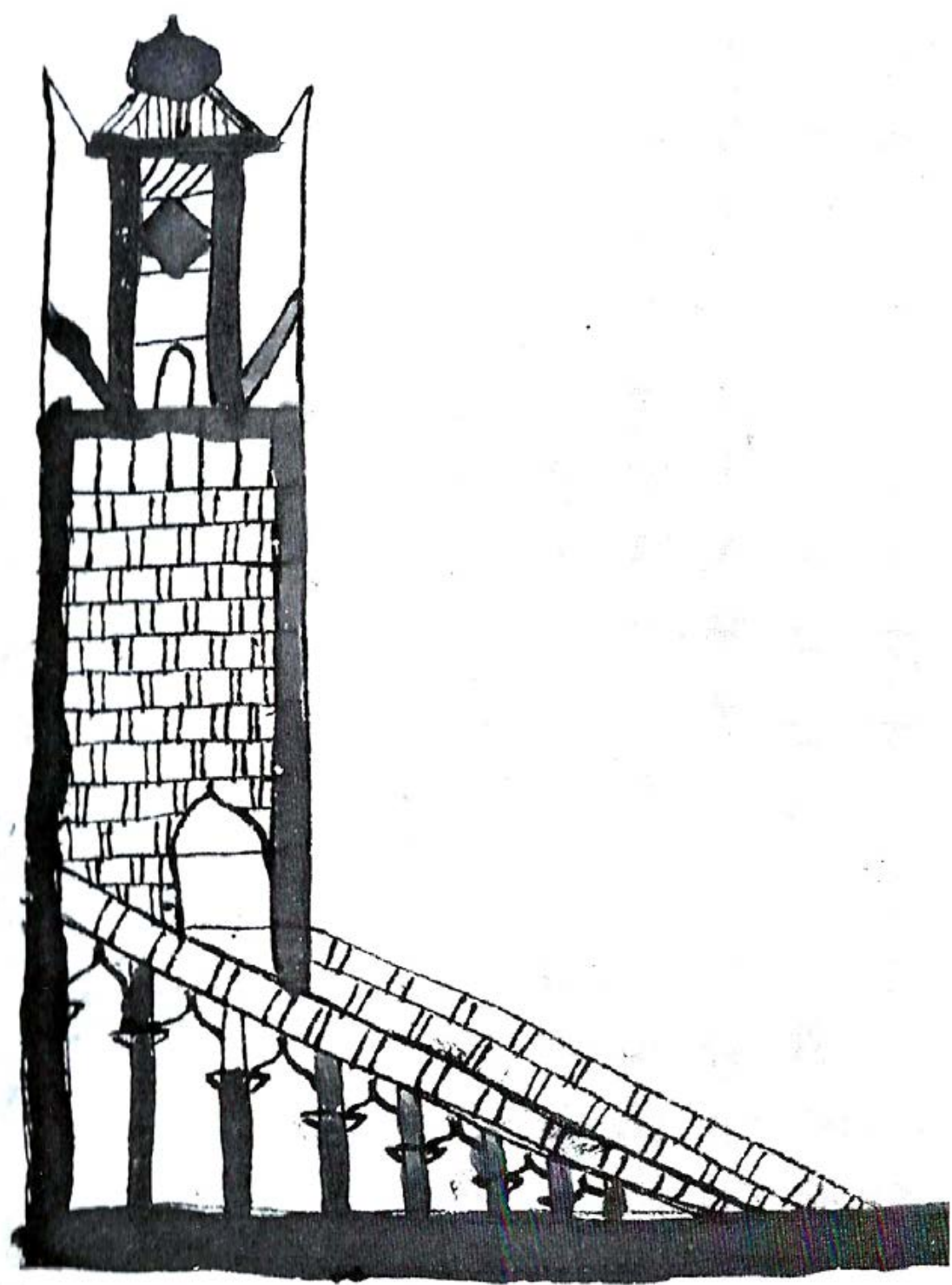

Fig. 1. Dibujo del Faro de Alejandría, en Abu Hamid al-Gharnati: Tuhfat alalbāb, 48. Bibliothèque nationale, Paris, Ar. 2168.

${ }^{3}$ Tuhfat al-albāb, pp. 70-72, misma obra publicada como Kitāb thamar al-albāb wa-zuhar al$a h b a \bar{b}$, Bibliothèque nationale, París, Ar. 2168. Ver edición con trad. y notas de Ramos (ed.), 1990. 


\section{MENCIÓN DE ALEJANDRÍA Y ALGUNAS DE SUS MARAVILLAS.}

\subsection{DESCRIPCIÓN DEL FARO}

En sus afueras está el Faro de Alejandría, que es una de las maravillas del mundo. Su parte inferior es cuadrada, de piedra tallada, sobre ésta hay un alminar octogonal y sobre éste hay otro redondo muy gracioso. La altura del primero es de noventa codos; el octogonal es igual a éste, y el pequeño es de treinta codos según esta ilustración.

En el interior del faro hay más de mil habitaciones entre grandes y pequeñas; las mayores están situadas en los ángulos del faro y las pequeñas entre los ángulos. EI viento pasa por todas ellas.

Se cuenta que sobre él había un espejo ${ }^{4}$, en el que se veía a quien llegaba por el Mar de los Rüm a una distancia de varios días y noches, según se cuenta. (Bejarano (ed.), 1991, pp. 155-158).

En el transcurso de su viaje de peregrinación a La Meca en 1165, Yusuf Ibn al-Shaykh al-Balawi, también llamado el-Andalusí ${ }^{5}$, un arquitecto malagueño, escribió un breve pasaje sobre Alejandría y su Faro, reseña que incluyó en su Libro del abecé -Kitāb alif $b \bar{a}^{\prime}-$, libro de tipo enciclopédico que concibió para poder transmitir a su hijo todos los saberes y conocimientos que consideraba necesarios. También conocido como Libro del alif y la $b \bar{a}^{\prime}$ para los juiciosos, fue hallado en una biblioteca de El Cairo en $1870^{6}$ y en él se encuentra la descripción más pormenorizada sobre el Faro de Alejandría tal y como se encontraba en aquella época, que el propio al-Balawi midió en persona.

Un problema importante deriva de las diferentes unidades de medida utilizadas por el viajero andalusí y su conversión a metros: shibr, dhirā', qāma, bā' y ashkil. Behrens-Abouseif ha realizado un pormenorizado estudio de esa conversión y sintetiza los datos extraídos de la descripción proporcionada por al-Balawi, que por otra parte resulta muy difícil de seguir precisamente por el constante cambio de esas unidades de medida, así que en lugar de recoger literalmente su descripción, apuntaremos los datos extraídos de ella (Behrens-Abouseif, 2006, pp. 4-7).

Lo que queda claro es que se componía de tres cuerpos. Al primero de ellos se accedía por una rampa de 68 metros de longitud, sobre 16 arcos crecientes en altura, de tal modo que la puerta de entrada del Faro estaba bastante elevada sobre la superficie del suelo, como queda también demostrado por la ilustración de al-Gharnati. El primer cuerpo habría medido 77,5 metros de altura, y su anchura habría sido de 30,6 metros en la base y de 26,3 en la parte superior, sobre la que se

${ }^{4}$ Según el propio al-Garnāțī, se trataba de un espejo de «hierro de China» de siete codos de longitud, en el que se reflejaba todo lo que llegaba por mar, procedente de Bizancio; y afirmaba que también se utilizaba para quemar las naves con el reflejo solar y para hacer señales a los navegantes. Ver Ramos (ed.), 1990, p. 47.

${ }^{5}$ Se puede encontrar nombrado de múltiples formas: Abu-l- Hayyay Yusuf al-Balawi ibn alSayj, y Asín Palacios lo nombra Ibn al-Xavj; ver Asin Palacios, 1933

${ }^{6}$ Yusuf Ibn al-Shaykh al-Balawi: Kitāb alif $b \bar{a}^{\prime}, 2$ vols., Cairo, 1287 [1870-71]. 
hallaría un parapeto de 2,5 metros de altura y 1,54 metros de anchura ${ }^{7}$. El segundo cuerpo habría tenido forma octogonal, con una altura de 37,5 metros y una anchura de 16,42 . Sobre este, habría otro parapeto, más ligero, de 44 centímetros de anchura, y en el centro se alzaría el tercer cuerpo, de forma cilíndrica, con 10 metros de altura y 8,7 de diámetro. Sobre esta última estructura original, se levantaba una mezquita-oratorio de 7,5 metros de altura y 4,3 de anchura, cubierta por una cúpula. El total del Faro se alzaría hasta los 132,5 metros de altura en el siglo XII.

Evidentemente, esta mezquita descrita por al-Balawi no formaba parte del diseño original del Faro. Este había sido restaurado entre los siglos XI y XII y fue entonces cuando se produjo su conversión en mezquita. Anteriormente, en el espacio ocupado por la estructura de esa mezquita-oratorio, se habría hallado la zona original en la que se encontraba el fuego, en el centro de un círculo de 8 columnas de granito que sostenían una cúpula cónica, coronada por una estatua de Zeus Sóter o Poseidón, según las imágenes representadas en las monedas alejandrinas de época romana y siguiendo también el influyente estudio realizado por Hermann Thiersch (Thiersch, 1909) [Figs. 2, 3 y 4]. Por consiguiente, la altura estimada del Faro original de época ptolemaica habría sido de unos 135 metros de altura. Otro viajero árabe, al-Masudi, había descrito ya el Faro (aunque no de forma tan exacta y sin medidas tan concretas) en el 933 o 934, y comentaba que la estructura superior original había sido demolida por orden del califa omeya al-Walid, en torno al 705-7158. La descripción realizada por al-Balawi coincide con la representación del Faro en un mosaico de la basílica de San Marcos, de en torno al año 1200 [Fig. 5].

Al-Balawi entendió la semejanza entre el Faro y algunas de las torres de las mezquitas más antiguas y de mayor tamaño, denominadas alminares (del árabe $a$ lmanāra, que significa "casa de luz», "faro»), y de forma más general minaretes, por los occidentales. La forma tradicional de los alminares construidos en Egipto tras la conquista árabe en el siglo VII, con base cuadrada, sección central octogonal y de forma cilíndrica en la parte superior, era la misma que la estructura del Faro ante la que habrían quedado asombrados al llegar por primera vez a Alejandría. Al-Balawi habría identificado igualmente los rasgos del Faro en los alminares de las mezquitas de Córdoba, en al-Andalus, o de Kairuán, en Túnez (Romer, 1996, p. 67; BehrensAbouseif, 2006, pp. 4-6). De hecho, participó en la construcción de varias mezquitas y pozos en su ciudad natal, y los temas religiosos y arquitectónicos predominan en su obra de carácter enciclopédico. En Alejandría, además del Faro, también tomó las medidas de las ruinas que quedaban del Serapeion y del Museion (Asin Palacios, 1932; 1933, p. 253).

${ }^{7}$ En las 4 esquinas de este parapeto se habrían hallado las 4 grandes estatuas de tritones que reflejan las monedas antiguas.

${ }^{8}$ Abu al-Hasan Ali ibn al-Husayn al-Masudi: Muruj adh-dhahab wa ma'adin al-jawhar (Las praderas de oro y las minas de gemas), 4 vols. (Beirut, 1988), vol. 1, 375ff. 


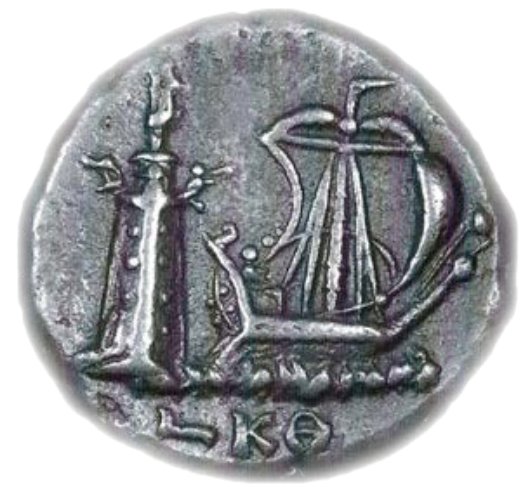

Fig. 2 Moneda de bronce de Comodo: Bibliothèque nationale de France, département Monnaies, médailles et antiques, Fonds général 2751.

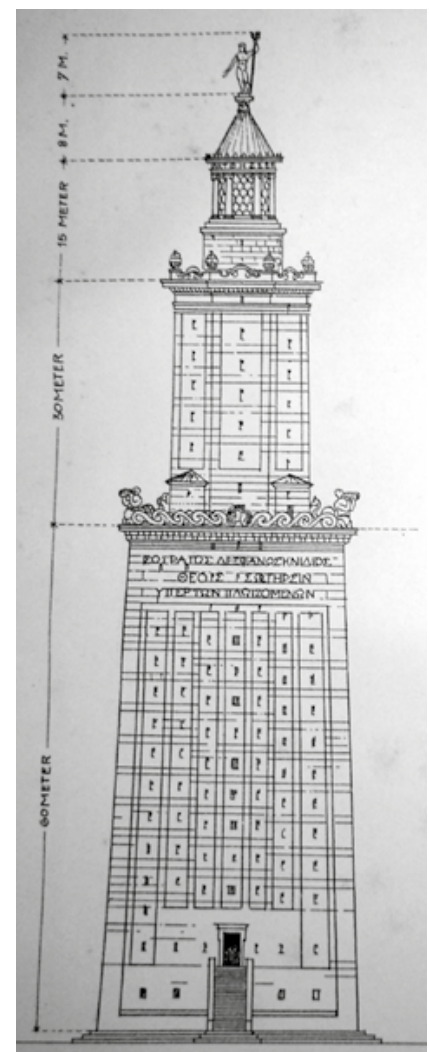

Fig. 3. Reconstrucción visual del Faro en época Ptolemaica según Thiersch, H. (1909). Pharos, Antike, Islam und Occident. Leipzig: B.G. Teubner.

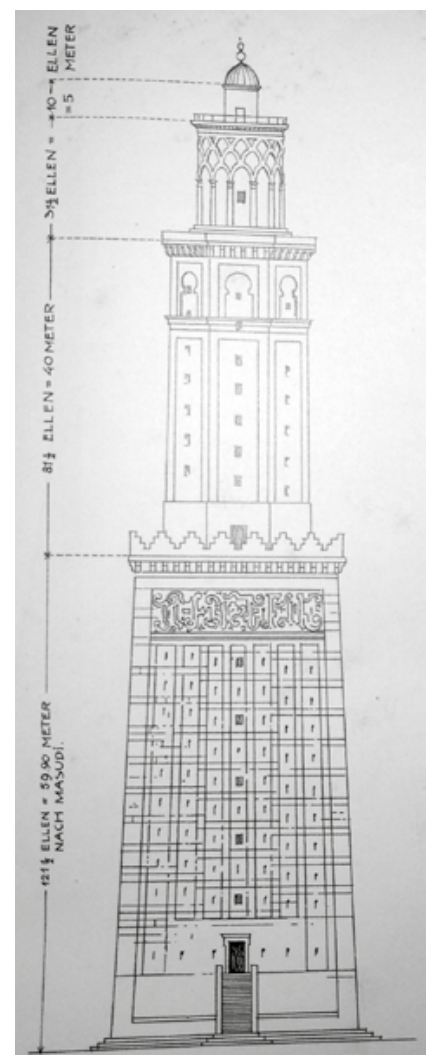

Fig. 4. Reconstrucción visual del Faro en torno al siglo X siguiendo la descripción de al-Masudi, según Thiersch, H. (1909). Pharos, Antike, Islam und Occident. Leipzig: B.G. Teubner. 


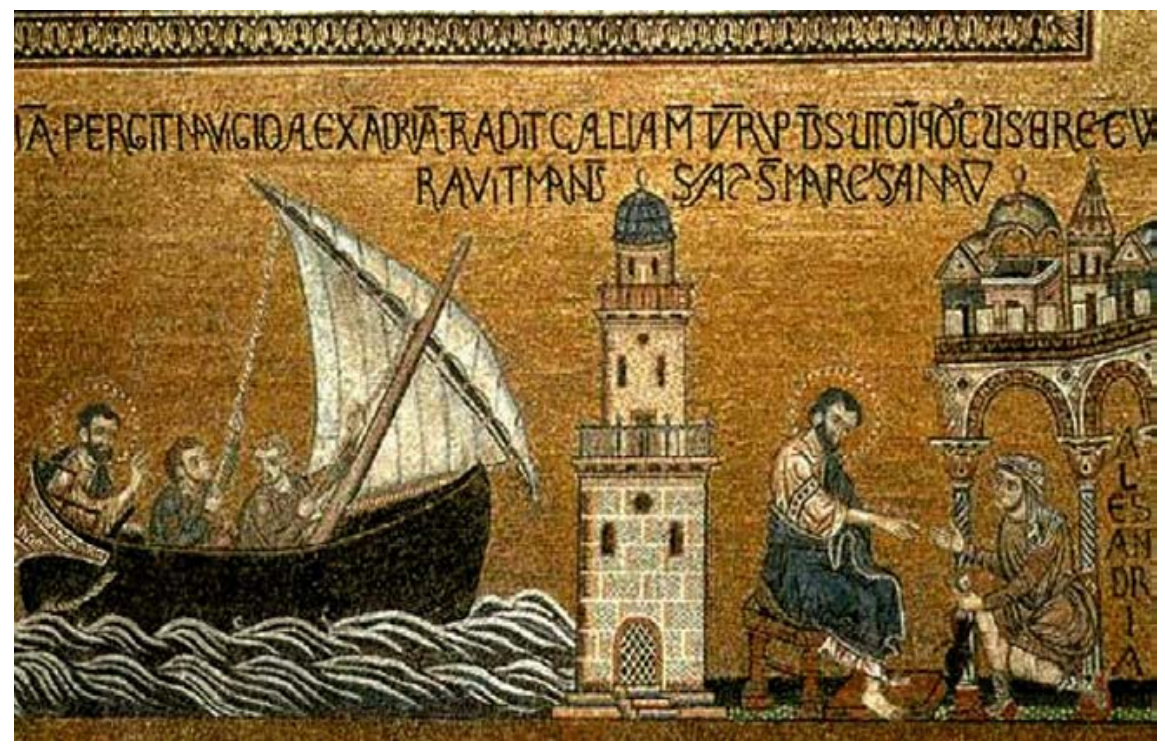

Fig. 5. El Faro de Alejandría representado en un mosaico de la basílica de San Marcos, Venecia (c. 1200).

Como ya hemos mencionado, el texto de al-Balawi fue hallado en una biblioteca de El Cairo en 1870, con una recepción muy tardía, que de hecho no va a empezar a manifestarse hasta que Asín Palacios lo dio a conocer y destacó su importancia a comienzos del siglo xx. Las descripciones de otros viajeros árabes, incluidos el andalusí al-Gharnati o el también mencionado al-Masudi, así como las representaciones del Faro en las monedas antiguas contribuyeron a la fijación de un modelo visual definido para esta maravilla de la mano de Thiersch. Igualmente, a comienzos del siglo xx, la aportación del testimonio de al-Balawi ha contribuido a plasmar ese modelo con medidas de mayor exactitud, en lo cual sin duda debió de pesar notablemente su formación como arquitecto.

\section{BENJAMÍN DE TUDELA}

Tan solo unos diez años más tarde del viaje de al-Balawi, en torno a 1175, Benjamín de Tudela, un rabino navarro, viajero y escritor, realizó todo un periplo desde su tierra natal hasta el Océano Índico, adelantándose en parte a lo que habría de hacer Marco Polo un siglo después. En este viaje tuvo la posibilidad de ver las pirámides de Egipto, las ruinas de Babilonia y el Faro de Alejandría, y de comparar las ciudades de Roma y Constantinopla. Tras esa gran travesía escribió su «Libro de Viajes ${ }^{9}$, en el que no solo describía los lugares visitados, sino que también ofrecía

\footnotetext{
${ }^{9}$ Editio Princeps en Constantinopla en 1543.
} 
información sobre las distancias, medios de transporte y otros datos prácticos, a la par que recogía leyendas y tradiciones orales, como ya señalamos.

Al describir las pirámides, lo hace identificándolas con la historia bíblica de los graneros de José ${ }^{10}$ [Fig. 6], una de las interpretaciones más frecuentes sobre las pirámides de Egipto a lo largo de toda la Edad Media, pues es más que posible que la noticia que tuviera de ellas en su Tudela natal estuviera condicionada por la Torah y por el desconocimiento de las fuentes antiguas referidas a Egipto, aunque parece probable que dominase el hebreo, el árabe, el latín, el griego y el romance (Amran, 2007, p. 15).

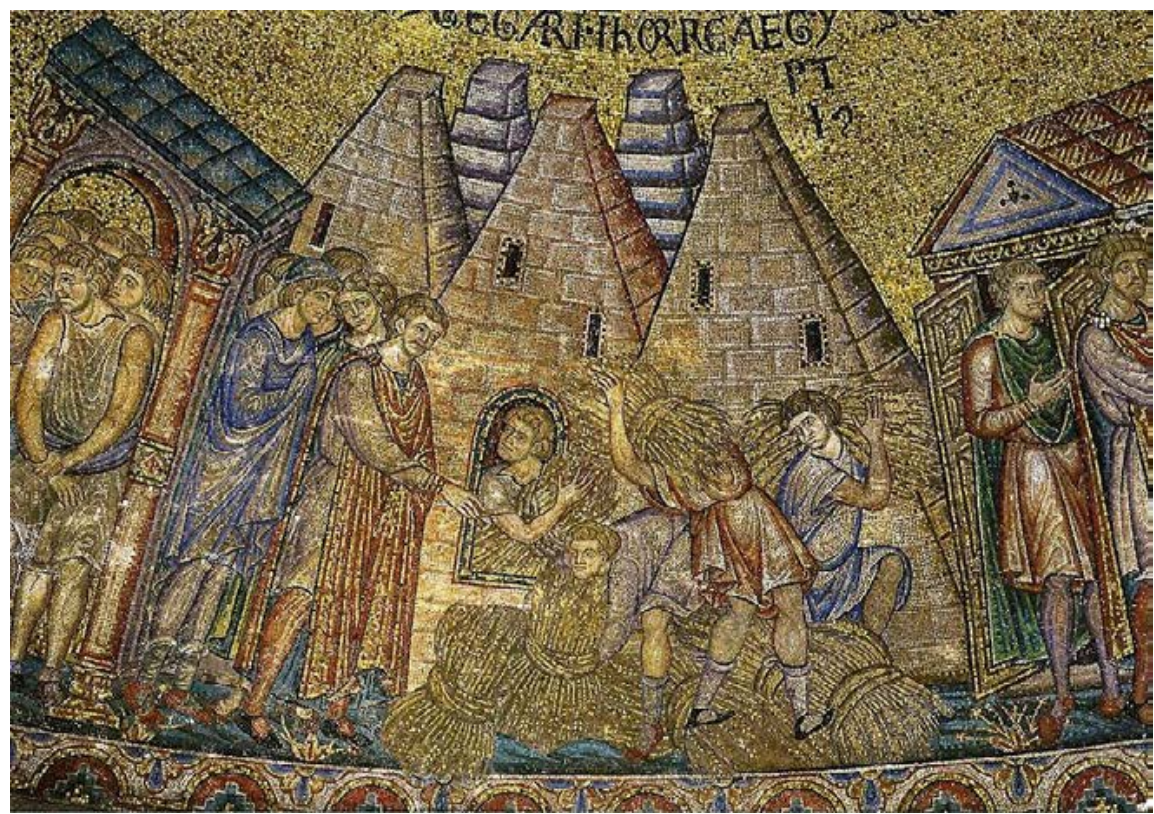

Fig. 6. Las pirámides de José en un mosaico de la basílica de San Marcos, Venecia (s. XIII). Licencia de Wikimedia Commons.

10 Según la identificación medieval que se basaba en el relato bíblico de José y el sueño del Faraón sobre las siete vacas flacas que devoraban a siete vacas gordas. José interpretaba este sueño como un anuncio de que a siete años de bonanza sucederían otros siete de escasez y hambruna, por lo que aconsejó al Faraón la construcción de grandes silos para almacenar todo el grano posible y afrontar así la carestía de alimentos. En época medieval, para intentar explicar la existencia de las pirámides en función de la única fuente de conocimiento totalmente válida, la Biblia (que en su Antiguo Testamento incluía la Torah judía), se las identificó con dichos silos. Por consiguiente, se las situaba bajo la influencia directa de José y del mismo Dios. Ver Génesis, 41-42. 
Destaca sobre ellas una más grande -posiblemente la Gran Pirámide- de la que no encuentra explicación sobre su método de construcción:

Existen aún en todos estos lugares muchos de los graneros construidos por José, fabricados con cal y piedras, construcción muy fuerte. Hay allí una pirámide hecha como por arte de encantamiento, no viéndose cosa semejante en otro lugar alguno; es de construcción fuerte. (Gonzalez Llubera, 1918, p. 112)

En dos ocasiones señala que estas edificaciones son "de construcción fuerte», lo que parece que le llamó la atención después de ver numerosas ruinas, como en Babilonia, a la que se refiere como «la antigua ciudad de Babel» y relaciona con Nabucodonosor (Gonzalez Llubera, 1918, p. 91).

Pero será refiriéndose a Alejandría cuando más datos aporte, ya que pudo ver el Faro con sus propios ojos, aunque recoge una leyenda de la tradición oral que no resulta muy creíble, y a la que ya había aludido al-Gharnațī (Bejarano, 1991, pp. 155-158):

Una gran torre, es decir, una almenara, que en árabe llaman Minar Aliskandría. En la punta de la torre puso un espejo de cristal colocado de modo que todas las embarcaciones que se dirigían allí para mover guerra y dañar la ciudad, fueran de Grecia o del Occidente, se reflejaban en el espejo de cristal a una distancia de veinte jornadas (...) Todavía el almenara sirve de señal a los navegantes, puesto que cuantos se dirigen a Alejandría desde cualquier lugar, la divisan de día desde una distancia de cien millas, y de noche enciende el vigía una antorcha, cuya llama ven los navegantes desde muy lejos, y se dirigen hacia ella. (Gonzalez Llubera, 1918, pp. 113-114).

La referencia a la «almenara» y, sobre todo, al nombre «Minar Aliskandría» es una de las primeras evidencias escritas de la relación del Faro con el alminar o minarete de la arquitectura islámica, junto a la reflexión del otro escritor hispánico que ya hemos mencionado, al-Balawi, realizada una década antes. Ambos contemplan el Faro en su misma apariencia reformada que incluía en su cúspide una pequeña mezquita-oratorio.

Por último, Benjamín de Tudela alude a las dos grandes urbes del momento: Roma y Constantinopla, esta última «capital del reino de todo el país de los griegos» (Gonzalez Llubera, 1918, p. 62), y Roma "la Grande, cabeza del reino de los cristianos (...) Existen además en Roma, otros muchos edificios y cosas, que nadie es capaz de enumerar» (Gonzalez Llubera, 1918, pp. 55 y 57). Esta idea que recoge

11 Viajes de Benjamin de Tudela, 1160-1173. Madrid: Sanz Calleja. Esta edición es la primera en castellano, aunque entre el siglo XVI y XVII aparecieron varias ediciones en latín, holandés y yiddish. 
Benjamín de Tudela es la que dará paso a las guías de viaje en las que se muestra Roma como lugar de peregrinación, y como ciudad llena de maravillas: los Mirabilia Urbis Romae, con un sentido muy similar a los relatos de maravillas árabes a los que ya hemos hecho alusión: los 'ayā'ib (Le Goff, 2008, p. 10).

\section{PEDRO TAFUR}

En la línea de la visión de Benjamín de Tudela, sobre todo en lo que respecta a la influencia del Antiguo Testamento en algunas de sus afirmaciones, se encuentra el testimonio del sevillano Pedro Tafur, que en su obra Andanzas y viajes ${ }^{12}$, escrita hacia 1454, recogió sus impresiones sobre los viajes que realizó por Europa y Oriente. En su segundo viaje visitó Palestina, Egipto y Bizancio, y como buen caballero cristiano, se centra en los lugares y hechos que le permiten afianzar su religión en contra del Islam (Molina Molina, 2011, p. 642). En los apuntes recogidos en este viaje es donde podemos encontrar su descripción de las pirámides, que una vez más aparecen descritas como los "graneros de loseph», situados en el desierto, a tres leguas del Cairo; pero, aunque pasa por Alejandría, no dice nada sobre el Faro, ya que en esa época ya se había derrumbado completamente ${ }^{13}$.

Fuemos a ver los graneros de loseph que están tres leguas de aquel cabo del río en el desierto, é bien que dicen que ay muchos mas adentro, pero allí non paresçen sino tres, dos grandes é uno non tanto, los quales son fechos á manera de un diamante con aquella punta arriba tan aguda; será el altura mucho más que la torre mayor de Sevilla; e por la puerta entrando dentro, un muro junto con el otro faziendo escalera en torno fasta llegar arriba, é todo lleno de siniestras; é como suben las bestias cargadas, descargan por aquellas siniestras é en esta manera los finchen fasta ençima; ciertamente non creo yo aver en el mundo oy tan grande edificio, nin yo non lo vi. (Tafur, 1874, pp. 86-87).

Hay que matizar que, aunque la visión medieval era prácticamente unánime en identificar las pirámides con los graneros de José, existieron excepciones que demostraron la mayor erudición de sus autores, al constatar que se trataba de sepulcros, como puede ser el caso de San Isidoro de Sevilla en sus Etimologías ${ }^{14}$, ya en

12 El libro de Tafur es conocido únicamente por una copia manuscrita del siglo XVIII, hoy en la Biblioteca Universitaria de Salamanca, Ms. 1985. Ver Lilao Franca y Castrillo González, 2002, pp. 309-310.

${ }^{13}$ Como señala el viajero árabe Ibn Battuta en 1349. Abu Abdullah Muhammad Ibn Battuta: Tuhfat al-anzar fi gharaaib al-amsar wa ajaaib al-asfar; comúnmente se lo conoce como Rihla de Ibn Battuta (El viaje de Ibn Battuta).

${ }^{14}$ San Isidoro de Sevilla: Etimologías, XV, 11, 3: «Pyramides genus sepulchrorum quadratum et fastigiatum ultra omnem excelsitatem quae fieri manu possit, unde et mensuram umbrarum 
el siglo VII. o el monje benedictino alemán Rábano Mauro ${ }^{15}$, en el siglo IX, que cita el texto de San Isidoro al pie de la letra. En el caso que comentamos, Pedro Tafur no fue un personaje al que se le pudiera reconocer una erudición semejante, por supuesto, lejana incluso del nivel de conocimiento general que podía tener Benjamín de Tudela, o el conocimiento técnico arquitectónico de al-Balawi. Las noticias que Tafur proporciona las extrae de sus propias impresiones en los viajes y su conocimiento está impregnado del bagaje cultural cristiano habitual en la época.

\section{PEDRO MÁRTIR DE ANGLERÍA}

Un caso completamente opuesto al de Pedro Tafur es el del humanista milanés Pietro Martire d'Anghiera, que vivió en la corte de los Reyes Católicos y fue conocido como Pedro Mártir de Anglería o el Milanés. Educado en Roma y posteriormente amigo de Cristóbal Colón, vivió en Granada y fue capellán de la reina Isabel, miembro del Consejo de Indias y Cronista de las Indias (Gozálbes Cravioto, 2003).

Como embajador de los Reyes Católicos, fue enviado al sultanato mameluco de Egipto en una misión efectuada en el año $1501^{16}$. El resultado de su viaje y de esta delegación.fue recogido en su obra Legatio Babylonica ${ }^{17}$. Precedida por un proemio, Legatio Babylonica es una compilación de tres cartas que recibieron los Reyes Católicos desde Alejandría entre 1501 y 1502, que es cuando tuvo lugar su embajada. En el libro o carta tercera el embajador cuenta que llega a El Cairo para discutir con el Sultán la precaria realidad de los cristianos orientales que estaban dentro de los territorios mamelucos, prometiendo una alianza con la corona española si se garantizaba su seguridad. Mientras esperaba la respuesta, Anglería recorrió las calles de la conocida como Babilonia de Egipto (El Cairo), y solicitó permiso para acercarse a ver las pirámides (Gozálbes Cravioto, 2003, p. 82).

egressae nullam habere umbram dicuntur. Tali autem aedificio surgunt ut a lato incipiant et in angusto finiantur sicut ignis; rũp enim dicitur ignis. Hos Aegyptus habet. Apud maiores enim potentes aut sub montibus aut in montibus sepeliebantur. Inde tractum est ut super cadavera aut pyramides fierent, aut ingentes columnae conlocarentur».

${ }^{15}$ Rábano Mauro: De Universo, XIV, XXVIII: De sepulchris: «Pyramides est genus sepulchrorum quadratum et fastigiatum ultra omnem excelsitatem quæ fieri manu possunt. Unde et mensuram unam umbrarum egressæ, nullam habere umbram dicuntur. Tali autem ædificio surgunt, ut a lato incipiant, et in angusto finiantur sicut ignis. Пũ enim dicitur ignis. Hos Ægyptus habet. Apud maiores enim potentes, aut sub montibus aut in montibus sepeliebantur. Inde tractum est ut super cadavera aut pyramides fierent, aut ingentes columnæ collocarentur».

${ }^{16}$ Esta embajada al Soldán (sic) de Babilonia fue estudiada en detalle por De la Torre (1936, pp. 443 y ss.) y García y García (1947).

17 P. Martyris Angli Mediolanensis Opera: Legatio Babylonica; Occeani decas; Poemata; Epigrammata, Edición de Antonio de Nebrija, Sevilla, Jacobo Cromberger, 1511. 
Así, las pirámides no escaparon al estudio del humanista, y ante un paisaje que describe como "maravilloso», Anglería narró su paseo por el Nilo antes de llegar al espectáculo de las pirámides, que le dejaron atónito. A la admiración visual por su tamaño, su altura y la extensión de su perímetro que llega a medir él mismo en unos «mil trescientos pasos ${ }^{18}$, se suman los misterios y secretos que guardan dentro de sus paredes:

El jefe de la expedición y yo miramos desde la boca de entrada. Hay un camino un poco en declive, resbaladizo, de mármol, de ciento ochenta pasos, angosto, por donde apenas se puede descender de rodillas, o si se va de pie, ha de ser con la cabeza inclinada bajo el vientre. Bajaron por él a indagar que había allí. Hallaron una cámara abovedada, de concha, de unos doce pasos, y dos fondos interiores adheridos a una cámara mayor. Hay un gran túmulo allí y, al ver también pequeños sepulcros, pensaron que sería la sepultura de algún hombre insigne y las de sus esposas, concubinas o hijos, pues dicen los historiadores que las pirámides fueron mansiones sepulcrales de los antiguos. $^{19}$

Este es uno de los primeros testimonios del interior de las pirámides ${ }^{20}$, y de ahí su gran interés, a la par que esa información lleva a Anglería a corroborar que se trata de sepulcros. Por otro lado, destaca aún más la magia y lo maravilloso de estas estructuras al recoger las impresiones de quienes le acompañaron en este viaje y subieron a las pirámides: «Estos contaron que, al mirar desde arriba, se les nublaban los ojos y que creían tener a sus pies mares y tierras ${ }^{21}$. Y cita también a Marcial, ponderando lo asombroso de estas estructuras: «Nos acercamos a ellas y,

18 Unos 910 metros aproximadamente, lo que se corresponde perfectamente con los 920 metros de perímetro de la pirámide de Cheops-Khufu.

19 Traducción de García y García (1947, p. 180), a partir del original en latín: Pedro Mártir de Anglería: Legatio Babylonica, III: "Ego autem et una mecum pronceps ex ostii faucibus despectamus. Est via leniter declivis lubrica marmórea angusta passuum CLXXX (uti aiunt) qua vix genibus flexis aut si pedibus inclinato ad uterum capite descendere liceat. Descendunt igitur: quid ibi sit quaeritant: forniceam cameram passuum forte duodecim testudineam atque penetralia duo maiori camerae inhaerentia in vacuo reperiunt. Ibi grandem tumulum in penetralibusque paruula sepulcra iacere animadvertentes insignem aliquem virum cum aut uxorum, aut pellicum aut filiorum (turba fuisse illic humatum uti etiam ab historicis proditur) existimarunt. Pirámides enim sepulcralia veterum habitacula fuisse legitur».

${ }^{20}$ La exploración interior de la gran pirámide se llevó a cabo en el año 815 por mandato del Califa Al-Mamun. Los datos sobre esta exploración se pueden encontrar en Barbier de Meynard y de Courteille (eds.), 1861, pp. 404-405.

${ }^{21}$ "Qui caligari sibi despiciendo oculos, mariaque ac terras sese sub pedibus habere existimansse, retulerunt». 
al verlas pensé que muy acertadamente vuestro poeta bilbilitano Marcial, cantó las maravillas de las pirámides» ${ }^{22}$.

Resulta de gran interés comparar estas impresiones con las que nos han llegado por parte de viajeros franceses a finales del siglo XVIII, algunas de ellas en relación con la campaña egipcia de Napoleón Bonaparte. Por ejemplo, el testimonio del teniente Nicholas-Philibert Desvernois, que escaló hasta la cima de la Gran Pirámide:

En la cima miras hacia abajo para ver una vasta extensión de terreno, un espectáculo más imponente del que podrías soñar. Hacia el Oeste, la vista se ensancha en la inmensidad del árido desierto desnudo, mientras que al Este el fértil valle del Nilo, todo verde con la vegetación, se extiende en la distancia. Comparada con la enorme mole de esta montaña de piedra, la gente a sus pies parece como insectos que se arrastran... Alrededor se alzan otras pirámides, una de ellas... aún está cubierta de unos 45 metros desde la cima con losas de granito rojo que son lisas y están pulidas como un espejo, haciendo imposible la escalada. (Desvernois, 1898, p. 258).

Y en cuanto al interior, tendríamos el testimonio del viajero francés Claude Savary, que viajó a Egipto en 1776 y que curiosamente ha sido considerado uno de los primeros en entrar en la Gran Pirámide, aunque ya estamos viendo que siglos atrás, primero los árabes y después el propio Anglería, ya lo habían hecho:

Dejamos nuestros abrigos a la entrada del pasaje que conducía al interior, y empezamos a descender, cada uno sosteniendo una antorcha encendida. Hacia el fondo, tuvimos que reptar sobre el pecho como serpientes para poder acceder a los pasillos interiores... Gateamos hacia arriba sobre las rodillas y al mismo tiempo presionando con las manos contra las paredes. Si no lo hubiéramos hecho así, corríamos el riesgo de resbalar hacia atrás y las pocas ranuras en su superficie no habrían sido capaces de detenernos si resbalásemos hasta el fondo. Hacia la mitad de la subida disparamos una pistola cuyo ruido ensordecedor no dejó de producir eco a través de todos los huecos del inmenso edificio. Esto despertó a miles de murciélagos, que cayeron sobre nosotros, golpeándonos en las manos y en la cara, y apagando algunas de nuestras antorchas. (Savary, 1785, pp. 185-186).

Resulta curioso comprobar que los testimonios de Anglería y de estos franceses sean tan similares, recogiendo prácticamente las mismas impresiones, aunque entre ellos medien casi trescientos años. La importancia de la expedición napoleónica y sus descubrimientos en relación con los estudios sobre Oriente fue tal que quizá se ha dado mayor relevancia a testimonios como los que acabamos de ver, cuando hemos podido comprobar que ni con mucho fueron los primeros ni aportan nada

22 «Has adimus: visas admiramur. Tunc Bilbilitani vatis Hispani vestri Martialis Carmen de pyramidum miraculis non inepte prolatum iudicavi». 
nuevo (en el caso del de Savary) en relación con lo ya recogido por Anglería en la embajada de los Reyes Católicos en 1501.

El testimonio de Pedro Mártir de Anglería fue recogido como fuente directa por Pedro Mejía cuando habla de "la historia de los Siete maravillosos edificios» en su obra Silva de varia lección, publicada por primera vez en Sevilla en $1540^{23}$. Su testimonio supone una fuente de primera mano para Mejía, que puede justificar de esta manera los datos que aporta como informaciones recabadas en primera persona y, por extensión, muy fiables por la proximidad en el tiempo, por la misma lengua de transmisión y por el mismo carácter humanista de ambos.

En este sentido, la obra de Mejía puede incluirse dentro del género de las enciclopedias y misceláneas cultivado por autores griegos y latinos y que continuó en la Edad Media, con ejemplos como las Etimologías de San Isidoro, que acabamos de citar, pero con la novedad de no estar redactada en latín, sino en castellano. Esta obra tuvo un gran éxito editorial en toda Europa, de forma que tuvo que ser ampliada en una segunda edición a finales del mismo año 1540 con diez capítulos añadidos a la tercera parte y se extendió de nuevo con una cuarta parte en la edición de Valladolid, de 1551. Se reimprimió 17 veces en el mismo siglo xvı y fue traducida al italiano en 1542, al francés en 1552 y al inglés en 1571 . En total, se pueden contabilizar 31 ediciones en español, y 75 en lenguas extranjeras, en el plazo de un siglo. La difusión aumentó de manera exponencial gracias a la imprenta, y la información cada vez resultó más accesible a un público mayor, pues ya se escribe en lengua vulgar.

La figura de Pedro Mejía, por otra parte cronista oficial del emperador Carlos $V$, es la de un humanista erudito, escritor y sobre todo historiador, que presenta un gran manejo de las fuentes: Aulo Gelio, Pomponio Mela, Estrabón, Heródoto... y sobre todo Plinio (Cherchi, 1993). El Ilamado por Francisco Pacheco «docto caballero" ${ }^{24}$, y autor de este "libro curioso» (Menéndez Pelayo, 1941), recogiendo las principales tesis del Humanismo, pretendió:

el rescate, la divulgación y la nacionalización de la cultura antigua, Mexía quiere imitar a los clásicos en el diseño y la realización de su obra y, al mismo tiempo, superarlos mediante la concentración y recapitulación de lo más granado de la cultura grecolatina, manejando él las fuentes de forma erudita y produciendo un texto nuevo que abarque y subsuma a todos los libros escritos por los antiguos. Mexía consigue, además, actualizarlos y hacerlos revivir en un contexto histórico y social -la España de la primera mitad del siglo xvı- que intentaba ser reviviscencia de una Antigüedad

${ }^{23}$ Utilizaremos la impresión de 1673, en Madrid, por Mateo de Espinosa y Arteaga. Ver también Lerner, 1982, pp. 677-684.

${ }^{24}$ Francisco Pacheco: Libro de descripción de verdaderos retratos de ilustres y memorables varones, Sevilla, 1599, publicado por vez primera por José María Asensio en Sevilla en 1870, fragmento al respecto en pp. 25-26. 
concebida míticamente y cuya organización política quería emular a la del legendario Imperio Romano. (Castro, (ed.), 1989, I, p. 73).

En este contexto, los capítulos XXXII a XXXIIII de la tercera parte, que hablan sobre las Siete Maravillas, se podrían considerar la primera enumeración prácticamente completa de lo que hoy consideramos lista "oficial o canónica» de las Maravillas del mundo antiguo, siguiendo sobre todo a Plinio, que ya habló de todas ellas incluyendo el Faro de Alejandría, y a quien Mejía utiliza como fuente principal, aunque a diferencia de la lista definitiva, recoge las Murallas de Babilonia en lugar de los Jardines Colgantes, que por otra parte también señala como alternativa.

Los edificios y obras que «por su grandeza y excelencia son llamadas las siete Maravillas del mundo" para Mejía son: las Murallas de Babilonia, el Coloso de Rodas, las Pirámides de Egipto, el Mausoleo de Halicarnaso, el Templo de Diana en Éfeso, el Zeus de Olimpia y el Faro de Alejandría. En el caso de la séptima maravilla, el Faro, el propio Mejía aclara que hay quien lo sustituye por los Jardines Colgantes, como acabamos de señalar.

En primer lugar, el autor justifica la necesidad de su trabajo al constatar la ausencia de una recopilación de las noticias acerca de las Siete Maravillas de la Antigüedad; él alude a las numerosas menciones que se hacen de ellas en muchas obras y autores, pero echa en falta una recopilación de todas ellas en un único trabajo, pues no conoce ninguno el respecto, "al menos en lengua castellana», matiza. Según la lista de Mejía, en tercer lugar aparecen las Pirámides, que el autor elogia en varias ocasiones como espectáculo difícil de creer. Explica su forma y su nombre, de nuevo aludiendo al vocablo griego para fuego $-\pi \tilde{u} \rho-{ }^{25}$, y cita numerosas fuentes: Plinio, Diodoro, Estrabón, Pomponio Mela, Heródoto, Amiano Marcelino y «otros mil». Se vuelve a identificar una gran obra como signo de vanidad, pues señala Mejía que las pirámides fueron vanidad de los Reyes de Egipto, quienes las construyeron «por dar de comer a las gentes, y en que trabajasen, y también por no dexar sus tesoros a sus sucesores», idea que recoge directamente de Plinio (Plinio: Historia Natural, XXXVI, 22), y también influenciada por el pensamiento de Aristóteles, quien relacionaba estas construcciones con la tiranía de los soberanos (Aristóteles: Pol. V, 1313ß). Aunque vuelve a hablar del personaje bíblico de José, no identifica

25 Del texto de Rábano Mauro, y por extensión del de San Isidoro de Sevilla, de donde está tomado, es la analogía de la forma piramidal con una llama: «Tali autem ædificio surgunt, ut a lato incipiant, et in angusto finiantur sicut ignis. חũp enim dicitur ignis», es decir, su elevación está construida de tal manera que en la base son anchas y estrechas en la parte superior, como el fuego. Con respecto a la forma de las pirámides y el fuego ver: San Isidoro de Sevilla: Etimologías, III, 12, 6: «Pyramis est figura, quae in modum ignis ab amplo in acumen consurgit; ignis enim apud Graecos $\pi$ ũ appellatur». Etimologías, III, 7, 5: «Solidus numerus est, qui longitudine et latitudine vel altitudine continetur, ut sunt pyramides, qui in modum flammae consurgunt, ita». Plutarco:

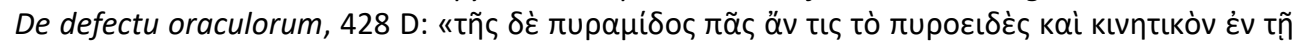

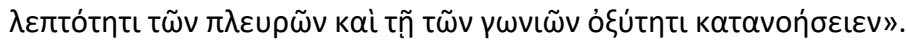


realmente las pirámides con los graneros, sino que utiliza su historia para resaltar la riqueza de los Reyes de Egipto ${ }^{26}$, distinguiendo a estas edificaciones como sepulcros de reyes, en la misma línea de Ravisio Textor ${ }^{27}$, al que no alude, y basándose en el testimonio directo del viaje de Pedro Mártir de Anglería. Se sorprende y destaca la cantidad de trabajadores e incluso alimentos que fueron necesarios para su construcción, como ya hicieron Heródoto y Diodoro ${ }^{28}$. Y es que precisamente, la mayor novedad en el tratamiento de las pirámides por parte de Mejía es la inclusión de una fuente directa y casi contemporánea suya, y para él de la mayor fiabilidad, al tratarse de un humanista como él, que ofrece así un testimonio de primera mano ${ }^{29}$.

\section{CONCLUSIONES}

En los siglos que ocupan la Plena y la Baja Edad Media, las dos únicas Maravillas de la Antigüedad que seguían en pie eran las Pirámides de Egipto y el Faro de Alejandría -si exceptuamos las ruinas del podio del Mausoleo de Halicarnaso o de las Murallas de Babilonia, abandonadas muchos siglos atrás-. Tal y como planteábamos al comienzo de este estudio, hemos indagado sobre los testimonios de viajeros de las diferentes culturas presentes en la Península Ibérica en relación con dichas

${ }^{26}$ De sus palabras: «Y dize Diodoro, que alrededor della, ni en muy gran trecho, no avia una piedra, ni guija, ni señal de aver andado allí hombre, ni señal de cimiento ni fundamento, sino arena menuda como sal», se desprende la influencia del texto del Génesis 41,48 y ss.: "José recogió todos los víveres de los siete años en que hubo abundancia en la tierra de Egipto y los depositó en las ciudades, almacenando en cada una los víveres de la campiña circundante. $Y$ almacenó trigo como la arena del mar».

27 Ravisius Textor: Officina, II, 248-251.

28 Heródoto: Historias, II, 124, 1 y ss. Hecateo de Abdera: FGr-Hist 264, en Diodoro: Biblioteca Histórica, I, 63, 2.

${ }^{29}$ Mejía, P. (1673). Silva de varia lección. Madrid: Mateo de Espinosa y Arteaga, III, XXXIII: «Dexados los libros antiguos, tenemos testigos de nuestros tiempos, Pedro Martin Milanes, varon docto, que fue por Embaxador de los Reyes Catolicos Don Fernando y Doña Isabel, al Soldan de Egipto en el año de mil y quinientos y uno, contaba después, y también dexo escrito en el libro de aquella su Embaxada, como el vio muchas de estas Piramides, y conformava lo que vio con lo que los libros dizen, y tenemos dicho, y señaladamente dize de dos dellas, que eran de altura increíble, y que midio los quadros de una dellas, y que tenia cada uno trecientos y quinze passos, y casi mil y quinientos en circuito, y que en cada parte están arruinadas, y sacadas piedras dellas grandissimas para otros edificios. Y dize mas, que algunos de su compañía con mucho trabajo, y en mucho espacio de tiempo pudieron subir a lo alto de una dellas, donde en lo ultimo y punta hallaron una sola llana por remate, y cabo tan grande, que cupieran en ella treinta hombres, los quales despues que descendieron, dezian, que les parecia estar en una nube, tan altos estaban, y que les parecia que perdian la vista, y se les desvanecia la cabeça, tanta era la altura de la Piramide, y assi va contando Pedro Martin esta cosa. Demanera, que dize, que no ay porque dudar de la copia de gente, ni lo demás que se dize averse ocupado en la labor destas Piramides». 
maravillas, constatando que dos viajeros árabes de al-Andalus, un viajero judío del Reino de Navarra y dos viajeros cristianos estuvieron en Egipto entre el siglo xII y el mismo comienzo del siglo XVI y nos dejaron a través de sus textos informaciones de primera mano pero diversa índole tanto del Faro como de las Pirámides.

Se pone de manifiesto la importancia del viaje como método directo de conocimiento sobre los monumentos antiguos y forma de contrastar las informaciones recibidas de fuentes más antiguas, ya fueran escritas o visuales. Por otra parte, hemos podido observar que la mayor o menor exactitud de los datos recogidos por esos viajeros en sus descripciones tiene mucho que ver con la diferente formación, el nivel cultural personal y la influencia del contexto religioso-cultural de cada uno de ellos. En este sentido, los datos ofrecidos por al-Balawi respecto al Faro de Alejandría son más cuantiosos y pormenorizados que los de su predecesor alGharnati, probablemente debido a su formación como arquitecto. El testimonio de una persona instruida, pero a la vez muy influida por su religión, como el del rabino Benjamín de Tudela, refleja hasta qué punto su percepción podía alejarse de una aproximación a los monumentos de carácter más científico. Sería un caso parecido al de Pedro Tafur, salvando las diferencias en su educación. Por el contrario, el relato de Pedro Mártir de Anglería es una muestra clara de las inquietudes y la formación cultural habituales en los humanistas del Renacimiento.

La riqueza de algunas de estas descripciones, que podría haber aportado mucho a la hora de la plasmación visual de estas maravillas, ha quedado diluida por los problemas en la recepción de algunos de los textos estudiados. Los textos escritos en árabe han tenido una difusión mucho más restringida, hasta su descubrimiento, traducción y recepción en el ámbito occidental, como en el caso observado de la obra de al-Balawi, y algo parecido ocurrió, aunque en menor medida, con la obra de Benjamín de Tudela. Sin embargo, las descripciones de los viajeros árabes, pese a su tardía recepción, han sido fundamentales para fijar el arquetipo del Faro, como se puede comprobar en la obra imprescindible de Thiersch, a comienzos del siglo xx. Finalmente, hemos puesto en valor la aportación de Pedro Mártir de Anglería en relación con su visita al interior de la Gran Pirámide, siglos antes de la expedición napoleónica que habría de cambiar tantas perspectivas sobre Egipto y el Orientalismo en general.

\section{REFERENCIAS BIBLIOGRÁFICAS}

Amran, R. (2007). El Libro de viajes de Benjamín de Tudela: del mito a la realidad histórico-geográfica. Cahiers d'études hispaniques médiévales, 30, pp. 13-24. https://doi.org/10.3406/cehm.2007.1794. 
Asín Palacios, M. (1932). El abecedario de Yúsuf Benaxeij el malagueño. Boletín de la Real Academia de la Historia, 100, pp. 195-228.

Asín Palacios, M. (1932). (1933). Descripción nueva del Faro de Alejandria. AlAndalus, 1, pp. 241-292.

Barbier de Meynard, B. y de Courteille, P. (Eds.). (1861). Al-Masudi: Prairies d'or, trad. Muruj al-dhahab. Paris.

Behrens-Abouseif, D. (2006). The Islamic History of the Lighthouse of Alexandria. Muqarnas, 23, pp. 1-14. https://doi.org/10.1163/22118993_02301002.

Bejarano, I. (Ed.). (1991). Abū Hāmid al-Garnāțī: Al-Mu'rib 'an ba 'd 'ayā'ib alMagrib.Elogio de algunas maravillas del Magrib. Madrid: CSIC.

Castro, A. (Ed.). (1989). Pedro Mexía: Silva de varia lección. Madrid: Cátedra.

Cherchi, P. (1993). Sobre las fuentes de la Silva de Pedro Mexía. Revista de Filología Española, 73(1/2), pp. 43-53. https://doi.org/10.3989/rfe.1993.v73.i1/2.554.

De la Torre, A. (1936). La embajada a Egipto de Pedro Mártir de Anglería. En Homenatge a Antonio Rubio i Lluch, I (pp. 443-450). Barcelona.

Desvernois, N.-Ph. (1898). Mémoires. Paris: Albert Dufourcq.

García y García, L. (1947). Una embajada de los Reyes Católicos a Egipto (según la "Legatio Babylonica» y el "Opus Epistolarum» de Pedro Mártir de Anglería). Valladolid: Instituto Jerónimo Zurita.

García Moreno, L. A. y Gómez Espelosín, J. (1996). Relatos de viajes en la literatura griega antigua. Madrid: Alianza.

Gonzalez Llubera, I. (1918). Viajes de Benjamin de Tudela, 1160-1173. Madrid: Sanz Calleja.

Gozálbes Cravioto, E. (2003). La visita a las pirámides de Egipto de un erudito renacentista: Mártir de Anglería. Boletín de la Asociación Española de Orientalistas, 39, pp. 79-87.

Le Goff, J. (2008). Lo maravilloso y lo cotidiano en el Occidente medieval. Barcelona: Gedisa. 
Lerner, I. (1982). Acerca del texto de la primera edición de la «Silva» de Pedro Mexía. En Actas del séptimo Congreso de la Asociación Internacional de Hispanistas: celebrado en Venecia del 25 al 30 de agosto de 1980 (pp. 677-684). Roma: Bulzon.

Lévi-Provençal, E. (2016). Abū Ḥāmid al-Ğharnāțī. Encyclopaedia of Islam, I. Brill [Online].

Lilao Franca, O., Castrillo González, C. (2002). Catálogo de manuscritos de la Biblioteca Universitaria de Salamanca. II. Manuscritos 1680-2777. Salamanca: Ediciones Universidad de Salamanca.

Mejía, P. (1673). Silva de varia lección. Madrid: Mateo de Espinosa y Arteaga.

Menéndez Pelayo, M. (1941). El magnífico caballero Pero Mexía. Estudios y discursos de crítica histórica y literaria (II, pp. 25-38). Santander: Consejo Superior de Investigaciones Científicas (CSIC).

Molina Molina, A. L. (2011). Pedro Tafur, un hidalgo castellano en Tierra Santa y Egipto. Cuadernos de Turismo, 27, pp. 641-662.

Pajón Leyra, I. (2011). Entre ciencia y maravilla. El géneroliterario de la paradoxografía griega, Monografías de Filología Griega 21. Zaragoza: Prensas Universitarias de Zaragoza. https://doi.org/10.26754/uz.978-84-15274-61-2.

Ramos, A. (Ed.). (1990). Abu Hamid al-Garnati (m. 565 / 1169). Tuhfat Al-Albab (El Regalo de los espíritus). Madrid: CSIC.

Romer, J. y Romer, E. (1996). Las siete maravillas del mundo. Historias, leyendas e investigación arqueológica. Barcelona: Círculo de Lectores.

Savary, C. (1785). Lettres sur l'Ègypte. Paris: Chez Onfroi.

Tafur, P. (1874). Andanças e viajes. Madrid: M. Ginesta.

Thiersch, H. (1909). Pharos, Antike, Islam und Occident. Leipzig: B. G. Teubner.

Villalba Ruiz de Toledo, F. J. (2005). El viaje de Don Pero Tafur (1436-1439). Arbor, 180(711-712), pp. 537-550. https://doi.org/10.3989/arbor.2005.i711/712.457. 